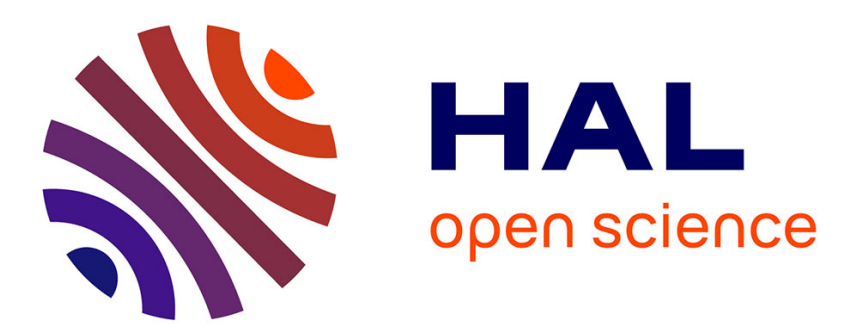

\title{
Business Model Implementation: The Antecedents of Multi-Sidedness
}

Ryan Rumble, Vincent Mangematin

\section{To cite this version:}

Ryan Rumble, Vincent Mangematin. Business Model Implementation: The Antecedents of MultiSidedness. Advances in Strategic Management, 2015, Business Models and Modelling, 33, pp.97 - 131. 10.1108/s0742-332220150000033021 . hal-01183388

\section{HAL Id: hal-01183388 \\ http://hal.grenoble-em.com/hal-01183388}

Submitted on 16 Oct 2015

HAL is a multi-disciplinary open access archive for the deposit and dissemination of scientific research documents, whether they are published or not. The documents may come from teaching and research institutions in France or abroad, or from public or private research centers.
L'archive ouverte pluridisciplinaire $\mathbf{H A L}$, est destinée au dépôt et à la diffusion de documents scientifiques de niveau recherche, publiés ou non, émanant des établissements d'enseignement et de recherche français ou étrangers, des laboratoires publics ou privés. 


\title{
Business Model Implementation: \\ The Antecedents of Multi-Sidedness
}

\author{
Ryan Rumble \\ Grenoble Ecole de Management (GEM) \\ Vincent Mangematin \\ Grenoble Ecole de Management (GEM)
}

\begin{abstract}
Business model research has long focused on external triggers, drivers, and enablers of business model adoption. What is less well known is how business models are adopted in practice. Using a conceptual framework developed by Baden-Fuller \& Mangematin, we propose 16 ideal types of business models. Based on a qualitative comparative analysis of 77 businesses, we explore the antecedents of these business model types, paying particular attention to multi-sided models, which are growing in prominence, and require businesses to manage complexity and interdependencies. Surprisingly, our analyses reveal that tools developed to support business design, creativity or visualization were systematically absent from the operationalization of complex, multi-sided business models. The paper contributes to our understanding in three ways: (1) it reveals how businesses with complex, multi-sided models are crafted using heuristics rather than rational business model design tools, (2) it highlights consistent relationships between the practices employed during business creation/reconfiguration and the business models that are adopted, and (3) it opens fruitful research avenues to develop tools to support heuristics in business design and implementation.
\end{abstract}

Keywords: business model, multi-sided, implementation, antecedent, configuration, heuristics, $Q C A$ 


\section{Business Model Implementation: The Antecedents of Multi-Sidedness}

\section{Introduction}

AirBnB, BlaBlaCar, Google, and Duolingo are examples of firms that operate multi-sided business models, where the value created for one set of customers/users depends on some kind of interaction with another set. As such, multi-sided models are conceptually more complex than single-sided ones. Advancements in internet technologies and changing expectations about the role of users have enabled the implementation of such models, but less is known about how these models are adopted in practice.

Extant research on the determinants of business model adoption has tended to focus on external factors. Industrial evolution changes the economic and institutional pressures put on firms, resulting in them having to find new ways to create and capture value in order to compete (Frankenberger et al., 2014). In particular, industry convergence has been highlighted as a key driver of new business model adoption, as companies attempt to access new markets while simultaneously having to deal with shifting competitive dynamics (Hacklin et al., 2009; Frankenberger et al., 2014; McPhillips \& Merlo, 2008). There is also a wealth of studies illustrating the roles of new and converging technologies - IT in particular in overcoming logistical constraints, thus enabling new ways to create and capture value (Baden-Fuller \& Haefliger, 2013; Björkdahl, 2009; Calia et al., 2007; Chesbrough, 2007a; Chesbrough \& Rosenbloom, 2002; Dubosson-Torbay et al., 2002; Hacklin et al., 2009; Timmers, 1998).

While external factors are influential, they do not fully explain the adoption of business models or their diversity. Firms adopt similar business models regardless of industry or firm size - consider low cost, mass-market models in both grocery retail and airlines. Conversely, firms in the same industry may operate dissimilar models - compare the longtail, e-business model of Amazon with the experience-based model of Waterstones (coffee, sofas, book clubs, etc.). While the adoption of certain business models is enabled by technological advancements, these same technologies are often available to competitors - yet the population of business model types within industries remains diverse. We should be aware of this when we consider whether technological, institutional and environmental pressures are sufficient to explain business model adoption. 
In addition to industry and technology, other studies have pointed to internal determinants of business model adoption. A central component of this internal perspective is managerial decision-making. The business model that a firm adopts has been portrayed as “... management's hypothesis about what customers want, how they want it, and how the enterprise can organize to best meet those needs, get paid for doing so, and make a profit" (Teece, 2010, p.172). The realized business is presented as an echo of management's assumptions and decisions (Shafer et al., 2005). Rather than design businesses from scratch, managers sometimes model existing businesses as templates or 'recipes' to follow (BadenFuller \& Morgan, 2010; Frankenberger et al., 2014, Sabatier et al., 2010), suggesting a relational view is more appropriate than one that is purely internal. In addition to external searches, firms' histories have also been shown to affect the business models they adopt, indicating path dependencies (Chesbrough \& Rosenbloom, 2002; Frankenberger et al., 2014).

Business model adoption, like strategy, is not just about choice but as much about suitability and fit. Managerial assumptions can be flawed, and inconsistencies within the business, or between it and the environment, may lead to the need to adopt another, better suited, business model if they are to survive (Frankenberger et al., 2014; Shafer et al., 2005). Furthermore, business model adoption can depend not only on the assumptions, expectations and sense-making of top managers, but also those of customers and/or other stakeholders (Chesbrough \& Rosenbloom, 2002). Therefore, viewing business model adoption simply as a managerial choice is insufficient - rather, such choices need to be reified via practice and tested in the market. If managerial choices represent the start of business model adoption, and the establishment of a sustainable business the outcome, then the practices involved in implementing a business model are the middle ground: but there is little literature on the means by which different business models are brought into being.

Academic literature has tried to understand the triggers, drivers, and enablers of business model adoption: in essence it asks why certain business models are adopted. In contrast, practitioner literature tends to emphasize how business models should be adopted, by offering anecdotal wisdom and guidance (Mullins \& Komisar, 2009; Osterwalder \& Pigneur, 2010; Reis, 2011). This disconnect highlights a gap in the current academic business model literature - from a scientific perspective, we know little about how different business models are made operational on a practical level. For example, we know that multi-sided models are enabled by internet technologies and that they can lead to rapid expansion (Hagiu, 2009), yet how entrepreneurs and managers incentivize multiple customer groups with varied motivations in an as yet unestablished business is under-researched. If business model 
research is to have policy or managerial application, scholars need to address this how dimension.

We treat business models as abstract ideal-types, which become operationalized through practice, and use Baden-Fuller and Mangematin's (2013) conceptual framework of business models as configurations of four key dimensions: customer identification, customer engagement, monetization, and value chain linkages. This paper analyzes the practices used in the implementation of each business model configuration, and compares them to explore the premises of their realization.

We performed a systematic comparative analysis of the implementation of 77 business models in 77 firms. We interviewed business founders in different industries to gain qualitative descriptions of their businesses, and the activities they used to develop them (henceforth referred to as antecedents). In order to analyze this data, we adapted the BadenFuller and Mangematin (2013) configurational framework to assign each business into one of 16 business model types, and then used Qualitative Comparative Analysis (QCA) to look for patterns of consistent association between particular business model types and certain antecedents. Our analyses found regular patterns between business models and antecedents. Surprisingly, complex, multi-sided business models were consistently associated with the absence of business design, creativity or visualization tools. We also discovered that the same antecedents were applied differently for different business models - as well as that similar antecedents led to radically different business models.

The paper contributes to our understanding in three ways: (1) it reveals how complex multi-sided business models are crafted using heuristics rather than rational business model design tools, (2) it highlights consistent relationships between the practices employed during business creation/reconfiguration and the types of business models that emerge, and (3) it opens fruitful research avenues to develop tools to support heuristics in business design and implementation.

\section{Business models and their operationalization}

The business model is a strategy concept that has been used to explain firm success (Montgomerie \& Roscoe, 2013), industrial evolution (Chesbrough, 2007b), and technological trajectories (Baden-Fuller \& Haefliger, 2013). Following Teece (2010), Baden-Fuller and Morgan (2010) emphasized the model aspect of business models. Models act as mediators between theory and practice, enabling scholars and managers to enquire about the world and 
to infer things about reality (Morgan, 2012), just as a model solar system allows us to determine the positions of the planets at a given point in time. By extension, business models are conceptual tools that enable us to enquire about how firms create value for customers/stakeholders and capture it for themselves. Managers can use business models to conceptualize and prototype new or changing businesses, or to map out competitive environments: and scholars can also use them to understand better how businesses function.

Following Baden-Fuller and Morgan's (2010) first business model definition, we look at business models as Weberian ideal types, each of which represents a configuration of theoretically-derived business model elements. An empirical business will fit (more or less) within the type to which it is most closely aligned. The implication of this definition is that firms neither own, create nor innovate business models - rather they operationalize them: as a concept, the model exists independently of how it is applied.

Business models can become operationalized in two ways: either they are applied when a new business is created (either as a new firm or business unit), or when an existing business is reconfigured, referred to as business creation or business reconfiguration ${ }^{1}$. Both involve the real-world establishment of value creation and/or capture mechanisms, but these terms should not be confused with the creation or innovation of a new conceptual type.

\section{Business Models and Multi-sidedness}

With regards to modelling, Baden-Fuller and Mangematin (2013) propose that we can categorize business models along four dimensions. (1) Customer identification is the mechanism by which firms sense, identify or even create customer groups. The process of customer identification might identify how technology is mobilized to create value for the customer, or the value proposition from the customer's perspective (Day \& Schoemaker, 2004). This dimension addresses multi-sided markets and the growing importance of big data as valuable information exchange (Casey \& Töyli, 2012; Eisenmann, Parker, \& Alstyne, 2006; Rochet \& Tirole, 2003; Rochet \& Tirole, 2008). In this paper, we focus on the two kinds of customer identification outlined in their framework: single-sided and multi-sided (where users and customers may be different). (2) Customer engagement (sometimes called the value proposition) encompasses the ways in which firms interact with their customers and create something of value to meet their needs. It also defines how the firm creates value;

\footnotetext{
${ }^{1}$ Business reconfiguration that results in the operationalisation of a new business model mirrors Markides' (2006) definition of business model innovation as "the discovery of a fundamentally different business model in an existing business" (Markides, 2006, p.20). However, we avoid this term since implies that it is the model that is innovating.
} 
whether it is standardized or tailored to customer requirements. When discussing this dimension we often refer to 'bus' (standardized, routine service) and 'taxi' (tailored journeys as and when needed, often at a higher price) models as illustrative analogies. (3) Monetization addresses how the firm captures value, an essential feature if the business model is to be sustainable (Rayna et al., 2014; Rayna \& Striukova, 2010). This dimension covers a range of topics including revenue streams, the timing of payments, and complementary assets that can increase appropriation (Teece, 1986). (4) Linkages and governance must also be considered for a robust business model concept. Business models articulate the architecture or governance of the business - i.e., those systems, routines and processes that the firm uses to deliver the product or service to the customer.

Each dimension covers a number of different business model elements (e.g. monetization may include subscription and/or simple exchange elements). The diversity of business models can be conceptualized as varied configurations of these elements. The paper is primarily concerned with the adoption of business models that contain multi-sided elements, as we expect them to be more demanding to design and implement than are singlesided models.

\section{Multi-sidedness and Complexity}

Complexity is an inherent dimension of business models - they will be more or less complex depending on the numbers and types of their constituent elements and their interrelations. Conceptual complexity is important, since it has general implications for stakeholders' ability to comprehend, manipulate or communicate a firm's value creation and capture mechanisms.

We define the complexity of a business model element as a function of (a) the number of its constituent parts, (b) the degree of their interrelatedness, and (c) their susceptibility to externalities (Reynolds \& Ruiz de Maya, 2013; Wood, 1986). Business model complexity refers to the overall complexity of a business model configuration - they will be more complex when they include multi-sidedness, and even more so when they include tailored customer engagement, and so on. Multi-sided models are more complex than single-sided ones, since they involve more than one customer/user group, and those groups are often interrelated (e.g. advertisers and readers in a free newspaper model). From an empirical point of view, Øiestad and Bugge (2014) focus on the implementation of new business models, and

highlight the additional managerial capabilities required to face changes in the publishing industry given the emergence of double-sided markets and the uncertainty of the new digital era. In the same vein, tailored models are more complex since they involve greater degrees of 
adaptability and of interaction between firms and their clients. Parmentier and Mangematin (2014) explored the challenges in developing new businesses that engage with user communities to tailor their offerings and accommodate those groups' specific needs. Complex business models can be beneficial in managing strategic tensions and paradoxes (e.g., being simultaneously low cost and high quality), but their effective management "depends on leadership that can make dynamic decisions, build commitment to both overarching visions and agenda specific goals, learn actively at multiple levels and engage in conflict." (Smith et al., 2010, p. 448). Implementing complex business models thus requires both agility and specialized managerial competences.

\section{Complex causality and overlap}

Baden-Fuller and Haefliger (2013), Baden-Fuller and Mangematin (2013), and Baden-Fuller and Morgan (2010) - among others - claim that business models are configurations of interdependent elements. As such, these authors argue that business models offer a holistic perspective; and appreciate that the addition, substitution or removal of a single element can influence the characteristics of the entire system (Aversa et al., 2015). This implies conjunctural causation, which in turn suggests that business models may also have causal heterogeneity (i.e., that different paths may lead to the same outcome) and causal asymmetry (i.e., if the presence of a condition leads to a certain outcome, the absence of that same condition does not necessarily lead to the absence of that outcome) (Schneider \& Wagemann, 2012). Such complex causality is important for our study, since we do not claim that certain antecedents will lead to multi-sided business models in a deterministic way. For instance, firms adopting business model $\mathrm{X}$ might all have used consultants to help in its development: but this does not imply that hiring consultants would lead to the implementation of business model X.

The notion of overlap relates to this configurational perspective. Business models that have numerous overlapping characteristics can be said to be similar, or close, to one another, and those with few overlapping areas to be different, or distant. We introduce the notion of overlap to help reveal and explain the extent of similarity (or distance) between business models. Business model overlap might be in general terms, or with reference to specific attributes, e.g., they may have similar financial impacts but otherwise be quite different from each other. The full implications of overlap, similarity and difference are not yet understood, and further research is needed in this area - but a number of possible effects can be posited. Closer models may be easier to combine within business model portfolios because they are 
likely to be synergistic. Business reconfiguration may be easier and less costly when moving between closer business models as they require similar resources or competences. Entrepreneurial success may be linked to the proximity between a new venture's business model and its founders' business model experience, even if they lack industry experience: an anecdotal example would be the successful subscription-based mail-order snack company Graze, which was founded by an employee of LoveFilm, the subscription-based mail-order DVD rental firm (Hurley, 2012). However, due to the complex causality just described, we may find that even similar models produce significantly different outcomes. We propose that there are two kinds of overlap - configurational and characteristic. Configurational overlap refers to the degree of coincidence between the elements that make up business models' configurations; those that share three out of four of their defining business model elements can be considered closer than those who only share single elements. Characteristic overlap is the degree to which business models share the same emergent qualities, or characteristics, such as antecedents, impacts, synergies, etc. We propose and empirically explore the notion that certain business models have consistent characteristics that are not restricted to their industrial contexts.

\section{Business Design and Implementation}

What antecedents are associated with the adoption of specific business models? Which practices are used in designing or implementing new or reconfigured businesses? In order to discover which practices lead to the adoption of which types of business models, we draw an analogy with the practices associated with innovation. The OECD Oslo Manual identifies different sources of innovation, from purely internal ones - based on formal or informal R\&D - to those based on external R\&D (patents, license, R\&D subcontracting etc.), and also emphasizes the role of external agents, suppliers and clients, as sources of innovation. Using the Oslo manual as a guide, we looked for studies in the business model field that focused on similar design, implementation, or collaboration practices. We adapted some of these practices so that they were relevant to business models in particular; for example, we focus on the design, creativity or visualization tools specifically related to business design, and provide examples of popular tools, such as the Business Model Canvas and the Board of Innovation. We also organized preliminary interviews to discover other prominent practices. These steps enabled us to develop questions and expectations about the kinds of practices that might be associated with the adoption of multi-sided business models.

This paper focuses on the practices over which managers have the most control - that 


\section{Antecedents of Multi-Sided Business Models}

is, the design and implementation practices they employ during the creation or reconfiguration of businesses. We explore a series of questions to try to discover whether certain business design and implementation practices are associated with the emergence of certain types of business models; and if so, how they are related.

\section{Questions}

In order to frame our research, we developed a number of questions about the relationships we expect to find between business models and their antecedents. The first three questions follow the same intuition - that, as multi-sided business models are conceptually more complex than single-sided ones, they will be associated with business design and implementation practices that attempt to manage that complexity.

First, we expect to see client participation in the development and implementation of multi-sided, networked models. Multi-sided business models involve the handling of multiple customer/user groups, while networked models imply that the firm has less direct control over the business model than under hierarchical governance systems. We therefore expect to find that firms planning to operate these kinds of models will be incentivized to work collaboratively with external actors. In multi-sided models the value one customer group extracts from the model is often tied to the behaviors or intentions of another (e.g. newspaper advertisers benefit as the numbers of readers increase), so that some customer groups may need to be incentivized to help ensure the focal firm's success and longevity. The firm and its key clients will likely be enticed to collaborate to implement a mutually-beneficial model. Since the kinds of value the firm and its customer groups might extract from the developing business are uncertain, we expect to find that emerging multi-sided businesses will adopt a 'discovery driven approach', involving experimentation and piloting (Chesbrough, 2010; McGrath, 2010), an approach that would be consistent with Reis' (2011) notion of lean startups, where constant piloting helps managers deal with uncertainty. Therefore we ask:

Question one: Are multi-sided, networked models associated with client involvement, feedback and piloting?

To operationalize multi-sided business models, tools may be required that enhance business design, creativity or visualization. Such models that have interrelationships between disparate customer groups may need their founders to come up with creative solutions to ensure they all remain incentivized. Multi-sided models will be harder to conceptualize and therefore may require visualization tools for both their communication and their manipulation. Further, 
developers of business model design tools also imply that their use may enable the management and design of complexity: “... computer-aided business model design might leverage the paper-based approach and allow for complex manipulation of business model elements." (Osterwalder \& Pigneur, 2010, p.263). Therefore:

Question two: Are multi-sided business models associated with the use of tools to enhance design, creativity, or visualization?

We also expect to find that multi-sided business models will consistently be associated with external search activities. We expect that the complexity associated with multi-sidedness means that it will be more difficult to predict business outcomes (Larsen et al., 2013), and that the more susceptible a business is to externalities will make its implementation more difficult. To overcome this uncertainty, we expect that the implementers of multi-sided business models will search for cases of other firms that have successfully operationalized similar models. External search activities could include reading about exemplar businesses in the business press - our preliminary interviews revealed that general internet browsing was a common theme. Baden-Fuller and Morgan (2010) suggest that one use of business models is as exemplars from which to learn, while Frankenberger et al. (2014) argue that imitation of other working businesses is a key factor in the development of open business models. Practitioner-orientated literature includes similar sentiments; Mullins \& Komisar (2009) advise managers to identify the 'analogs' and 'antilogs' of their prospective business for an evidence-based approach to business design. Furthermore, managers often use such external, professional agents as consultants and incubators to provide them with expert advice. This leads us to our next question:

Question three: Are multi-sided business models associated with external search activities?

The full implications of overlap are not yet known. Because of the configurational and synergistic nature of business models, and the complex causality implied in their functioning, we expect to find that that similar practices will not necessarily generate similar types of business models, as opposed to there being a more linear relationship.

Question four: Do similar antecedents necessarily lead to similar business model configurations?

We now explore these questions empirically. 


\section{Data and methods}

\section{Cases}

In order to explore and answer our research questions, we conducted 77 mini-cases of businesses from small and medium-sized European enterprises that had been operating commercially for at least two years. We selected firms from multiple industries to see if business model characteristics were consistent across industries (see Table 1) - reasoning that, if they were, our findings would further legitimise the use of the business model as a unit of analysis and strengthen the explanatory power of the concept. Since it was necessary to interview those involved in the design and implementation of new or reconfigured business, the database consists mostly of young firms under fifteen years old. ${ }^{2}$

Table 1: Cases and data collection

\begin{tabular}{|c|c|}
\hline \multicolumn{2}{|l|}{ Case overview } \\
\hline Cases & 77 European businesses \\
\hline Firm age & 2 - 19 years old \\
\hline No. of employees & $\begin{array}{l}\text { Predominantly SMEs with between } 10 \text { - } 130 \text { employees. Two large firms ( } 320 \text { and } 379 \\
\text { employees) }\end{array}$ \\
\hline Industries & $\begin{array}{l}\text { ICT and analytics (13 cases), consumer retail (12), entertainment and creative industries } \\
\text { (10), business support (10), catering ( } 9 \text { ), marketing (5), consumer goods manufacture (5), } \\
\text { consumer services (5), finance (3), transport (2), real estate (1), elderly care (1), and } \\
\text { agriculture (1) }\end{array}$ \\
\hline Business models & 14 business model types \\
\hline \multicolumn{2}{|l|}{ Data collection } \\
\hline No. of interviews & 77 (one per case) \\
\hline Interviewees & Business founder, almost always the CEO \\
\hline Interview length & 30 minutes (average) \\
\hline Archives & $\begin{array}{l}4 \text { hours (average) of web-based archival search per case to deepen case knowledge and } \\
\text { corroborate interviews }\end{array}$ \\
\hline
\end{tabular}

We used a maximum variety sampling method designed to cover a diverse range of business model configurations for comparative analysis: thus, if we had recently interviewed a firm with a single-sided, hierarchical model, we would then search for a multi-sided network, then a multi-sided hierarchy, and so forth. This variety helped reduce the problem of logical remainders in our later analyzes. Since firms were not selected using random sampling methods, we cannot make statistical generalizations, but we argue that this should not affect the validity of our theoretical contributions (Fiss, 2011; Yin, 2009). Furthermore the method of analysis we use (QCA) does not require random sampling, since calibration is driven by theory rather than by the descriptive qualities of the data (Fiss, 2011).

\footnotetext{
${ }^{2}$ Although this does not necessarily have to be the case - new business models can be adopted by firms of any age.
} 
Although our questions focus on multi-sided models, we capture and analyze other business model elements in our study. This is for two reasons: (a) the study is exploratory, and (b) we assume conjunctural causality. The implication of the second point is that multisided models may indeed have consistent relationships with certain antecedents, but only in the presence or absence of other elements - so, rather than study multi-sidedness in isolation, we needed to analyze it as part of a holistic configuration of elements.

\section{Data Collection}

We interviewed senior managers involved in the design and implementation of new or reconfigured businesses in spring 2014 using a semi-structured interview guide designed to yield qualitative descriptions of business models' elements as well as their antecedents. Interviewees were asked open questions designed to prompt them to describe each of BadenFuller and Mangematin's (2103) business model dimensions in turn so that we could later assign them to a set.

Interviewees were then asked to rate each item on a list of antecedents (derived from our questions) according to how extensively it was utilized in their business creation/reconfiguration processes on a 4-point scale (used extensively; used moderately; used to a small extent; not used at all). Question one concerns the testing and experimentation of multi-sided business models so that they could fit the needs of multiple customer groups simultaneously, so the antecedents we searched for were (a) client involvement in the business design/implementation process, (b) piloting the new business, and the gathering of (c) qualitative or (d) quantitative feedback. Question two attempts to discover whether, since multi-sided business models are conceptually complex, managers use (e) business design, creativity and visualization tools to conceptualize, manipulate or communicate the structure of their firm. Question three enquires whether, as multi-sided business models are risky and uncertain, managers perform external search activities to learn from the examples of others, which might include (f) reading the business press, $(\mathrm{g}$ ) browsing the internet, or (h) seeking advice from external professional agents (see Appendix A for the full list of antecedents). In addition to rating each antecedent, interviewees were also asked to comment on how they performed these activities (if they did) and why.

Interviews were selected as an appropriate data collection method, as they reveal nonpublicized information about internal activities. Questions were designed to gain an objective image of a firm's business model activates rather than to capture managers' own business model conceptualizations. Respondents' answers about the nature of their business models 
were triangulated - where possible - using archival data from the public domain.

If the interviewees gave several different answers for each business model element within the same company, we took this as an indication that its business model portfolio included multiple business models (Sabatier et al., 2010). Given the complexity involved, we ultimately had to make reasoned decisions during the interviews about where to make the distinction between models. For instance, a firm may have several payment options, but in all other respects be fairly uniform - in which case we considered that it only operated a single business model. Alternatively if those different payment options were associated with different customer segments and degrees of customer engagement, then it would be considered as operating multiple business models. For the purposes of this study we only selected one business model per company for analysis. Once the business models had been identified, interviewees were asked to refer only to the business creation/reconfiguration process of the selected business model when ranking and describing antecedents.

\section{Data Analysis}

We chose to use QCA for our analyses. It was ideal for our study since it allowed us to retain a configurational perspective when exploring the relationships between business models and other conditions. It does this in a holistic manner, since it treats all logically possible configurations as separate units of analysis. Another feature of QCA is that it accounts for complex causality, i.e., it allows us to see if there are multiple, configurational, asymmetric relationships between business model types and antecedents (Ragin, 1987; 2000; 2008; Schneider \& Wagemann, 2012). Furthermore, it is well-suited to medium-n comparative analysis. We ruled out the use of regression-based methods, ${ }^{3}$ since they are unsuitable for mapping the non-linear and conjunctional causal relationships we expected to find (Fiss, 2007, 2011; Grandori \& Furnari, 2008).

Those using QCA customarily examine what combinations of conditions cause an outcome. In this study, however, what would conventionally be called an outcome (i.e., an antecedent) occurs before the combination of conditions (the operationalized business model configuration) that we examined. ${ }^{4}$ As such, while 'outcome' is the established term in QCA, I refrain from using it here in favor of the term 'antecedent'. This does not pose a

\footnotetext{
${ }^{3}$ We would like to clarify that, although regression-based methods are unsuitable for measuring business model configurations, they may be used to contribute to the field using other units of analysis.

${ }^{4}$ Furthermore - although not within the scope of this paper - the direction of causality is not clear: antecedents may influence business model adoption, but the converse might also be true - that people have an idea of the kind of business model they want to adopt and select appropriate design activities.
} 
methodological problem, and the focus of our analysis remains superset/subset relationships, although we had to be mindful of this reversal when inferring insights from our findings and careful not to fall back on standard interpretations of results.

Our data analysis went through three stages. First, we coded the interviews and assigned four fuzzy-set scores to each case based on what kinds of business model were indicated. Next, we performed comparative analyses to see which business model configurations were consistently associated with what kinds of antecedents. Third, we went back to our interviews to see if we could explain or elaborate on these results. We now outline each of these stages.

\section{Typology}

We adapted Baden-Fuller and Mangematin's (2013) four business model dimensions to create a sixteen-type typology that is abstract enough to be applicable in any industry or market, so enabling comparative analyses. While it was tempting to add more conditions for further granularity, this would have increased the likelihood of logical remainders (possible configurations that did not align with any of our observed cases) in our analyses (Rihoux \& Ragin, 2009). Our typology is configurational in nature and so was suitable to answer our questions, and could easily be applied to QCA.

The original framework needed to be adapted in order to aid consistent categorization with clearly demarcated boundaries. We achieved this by assigning each business model dimension an element which might or might not be present. Our literature review revealed that the absence of an element tended to imply the presence of an opposing one (see Table 2). As outlined earlier, one of the elements for each dimension represented a more conceptually complex state, while its opposite referred to its simpler counterpart. Based on earlier definitions of complexity (Reynolds \& Ruiz de Maya, 2013; Wood, 1986), we argue that business model elements can be considered complex if they have more components, interrelations and are more susceptible to externalities.

Table 2: Business model elements and conditions

\begin{tabular}{|l|l|l|}
\hline \multicolumn{1}{|c|}{ BM dimension } & \multicolumn{1}{c|}{ Complex element } & \multicolumn{1}{c|}{ Simple element } \\
\hline Customer identification & Multi-sided market & Single-sided market \\
\hline Customer engagement & Tailored, project based & Standardised, scaled \\
\hline Monetisation & Repeat payments & Single payments \\
\hline Linkages & Networked structure & Hierarchical structure \\
\hline
\end{tabular}


While our typology has two conditions per business model dimension - one element and its counterpart - we only used the complex elements in our analyses. QCA is concerned with the presence or absence of a condition, and referring to opposing conditions is strongly discouraged, since the method operates under the assumption of asymmetry of sets (Ragin, 2008). Therefore, in QCA the opposite of multi-sided is not single-sided, but 'not multisided' (i.e., the absence of multi-sidedness). For our purposes, however, the elements and their opposites are established in the business model literature, logically implied, ${ }^{5}$ and are implicit in our coding structure. Therefore 'not multi-sided' is for all practical purposes synonymous with 'single-sided'. For our analysis we complied with the convention of only referring to the presence or absence of four complex elements; multi-sided markets $(\mathrm{M})$, tailored services $(T)$, repeat payments $(\mathrm{R})$, and networked structures $(\mathrm{N})$. However, in order to bring greater clarity and aid the interpretation of our results, we refer to the simpler elements in our discussion.

\section{Table 3: Fuzzy-set calibration of business model elements (conditions)}

\begin{tabular}{ll}
\hline Multi-sided market \\
\hline 0.00 & Single-sided; appeals to a single or generic customer segment (e.g. newsagents) \\
0.33 & Multiple customer groups that are unrelated (matinées appeal to students \& seniors) \\
0.67 & Two customer groups with positive spill-overs (breweries sell to pubs and consumers) \\
1.00 & Model dependent on multi-sidedness (free newspapers) \\
\hline \multicolumn{1}{l}{ Tailored customer engagement } \\
\hline $0.00 \quad$ Standardised, scaled model (factory) \\
$0.33 \quad$ Minor, automated or self-customisation (social media, deli counter) \\
$0.67 \quad$ Major but limited customisation (kitchen installation) \\
$1.00 \quad$ Unique, project-based services (consulting) \\
\hline Repeat payments \\
\hline 0.00 & One-time payment (fast food) \\
0.33 & Complementary payments optional (regular optional upgrades) \\
0.67 & Complementary payments expected (razor and blade) \\
1.00 & Contractual repeat payments (mortgage) \\
\hline Networked structure \\
\hline 0.00 & Hierarchy (supermarket) \\
0.33 & Outside actors under hierarchical control (franchise) \\
0.67 & Restricted network (brokers) \\
1.00 & Open network (social media) \\
\hline
\end{tabular}

\footnotetext{
${ }^{5}$ e.g., assuming there cannot be a zero-sided model, a firm that is not multi-sided must be single-sided.
} 
Business models that contain a certain condition are said to be in that condition's 'set'. Rather than being fully in or out of a set, many businesses would more accurately fit somewhere on a continuum between in and out. In order not to lose this subtlety in our analyses, we made the distinction between in and out into fuzzy-sets using a four-point scale: giving a score of 0 to business models outside the set; 0.33 for BMs that are mostly but not fully outside the set; 0.67 for those mostly but not fully inside the set; and 1 for those that are fully within the set (Ragin, 2000) - e.g., a business model that is assigned a score of 0.67 for tailored engagement is one that is more within than out of the tailored engagement set, but does not fully meet the criteria of that set. The fuzzy-set scores of each condition were defined to ensure consistency (see Table 3). Thus each business model was assigned four fuzzy-set scores indicating the presence or absence of the four conditions, so that each case's business model is defined as a configuration of those scores.

\section{Assigning scores to each case}

The interview data was coded to highlight the business model elements, and then each element was assigned a fuzzy-set score. Each business was categorized conclusively after the data collection phase in an effort to keep the interviews exploratory, so that interesting findings would not be overlooked. The collection of descriptive data was also used to check the final assignment of fuzzy-set scores for consistency.

The use of each antecedent was calibrated using a four-point fuzzy-set scale for the set 'extensive use of [antecedent]'. A score of 1 was given to those antecedents the respondents said they used extensively, 0.67 to those they used moderately, 0.33 to those they used to a minor extent, and 0 to those they did not use at all. This means that we consider those antecedents that respondents reported using to a minor extent to be more out of the 'extensive use of [antecedent]' set than in it (although the antecedent was used, it can hardly be said to have been used extensively).

\section{Comparative analysis}

We used QCA to analyze the business model configurations for each antecedent individually using the fs/QCA software program (Ragin \& Davey, 2014). Both the presence and absence of the 'extensive use' set were tested. We first performed tests for necessity before conducting our sufficiency analyses using a consistency cut-off point of $\geq .8$, greater than Ragin's (2006) minimum suggestion of $\geq .75$. We set a threshold of 2 or more observed cases per configuration in order to be included in our analyses. This reduced the number of configurations with observed cases from 14 to a still acceptable 10. A cut-off point of 3 


\section{Antecedents of Multi-Sided Business Models}

would have reduced the number of cases to 6 , meaning more than half of the logical configurations would have lacked empirical support. A cut-off point of 2 for a dataset of 77 cases aligns with the current QCA conventions in management studies; Fiss (2011) for example selects a frequency cut-off of 3 for over 200 observed cases. In the absence of strong theoretical reasons we made no simplifying assumptions during the counterfactual stage of our analysis. We next contrasted the results of the analyses against each other to explore emerging themes related to our questions, or more broadly to the theme of business model complexity. As previously mentioned, we do not claim to show causality, but instead seek to demonstrate areas of uniform association between business models and their antecedents. Therefore consistency and coverage scores are only used to establish superset/subset relationships.

\section{Going back to the cases}

Following QCA methodology, we then went back to our empirical cases to try to explain these findings. Rather than examine every case, we focused on those solutions that agreed with or challenged our expectations. We systematically reviewed the data for every case company that was covered by the QCA solution to look for relevant evidence that either supported or contradicted our expectations, or that could provide some kind of explanation.

\section{Results}

We present our results in tables using the notation outlined in Ragin and Fiss (2008). The presence of a condition is indicated by a black circle - ' $\bullet$ ' - whereas its absence it indicated by an open circle with a cross - ' $\otimes$ '. The size of the circle indicates whether the condition is core (large) or peripheral (small). Conditions where the presence or absence of a condition is irrelevant (so called 'don't care' conditions) are indicated by empty spaces. Solutions are grouped and labelled by their core conditions and are ordered by their unique coverage score. In the text I use standard Boolean notation where two letters together are linked by a logical AND, ' + ' indicates logical OR and ' $\sim$ ' indicates logical NOT. Therefore $\mathrm{AB}+\sim \mathrm{C}$ should be read as $A$ and $B$ or not $C$ (Schneider \& Wagemann, 2012). We present our results using the panel approach developed by Greckhamer (2011) to compare multiple fuzzy-set analyses. Where there are multiple path solutions, we highlight the empirically dominant configuration (i.e. the one that has the highest unique coverage), again following Greckhamer's (2011) style. 


\section{Antecedents of Multi-Sided Business Models}

\section{Consistent Patterns of Association}

A necessity analysis performed on each antecedent found that there were no necessary business model elements that explained the presence or absence of any antecedents. The results from the sufficiency analyses are given below. The presence of seven antecedents and the absence of one had consistent superset relationships with certain business model configurations (see Tables 4 and 5). Two antecedents - Feedback (solution coverage $=.80$ ) and Client involvement (solution coverage $=.73$ ) - showed multiple parsimonious solutions.

Table 4: Analysis of antecedents

\begin{tabular}{|c|c|c|c|c|c|c|c|}
\hline \multirow[b]{2}{*}{ Configuration } & \multicolumn{3}{|c|}{ Internet } & \multirow{2}{*}{$\begin{array}{c}\text { Data } \\
1\end{array}$} & \multirow{2}{*}{$\begin{array}{c}\text { Ext. } \\
1\end{array}$} & \multirow{2}{*}{\begin{tabular}{c|} 
Text \\
1
\end{tabular}} & \multirow{2}{*}{$\begin{array}{c}\text { Pilot } \\
1\end{array}$} \\
\hline & $1 \mathrm{a}$ & 1b & 1c & & & & \\
\hline Multi-sided market (M) & 0 & 0 & O & 0 & 0 & 0 & 0 \\
\hline Tailored engagement $(\mathrm{T})$ & & 0 & $\otimes$ & 0 & & $\bullet$ & 0 \\
\hline Repeat payments (R) & & $\otimes$ & - & - & $\otimes$ & & $\otimes$ \\
\hline Networked structure (N) & $\bullet$ & & & & $\bullet$ & $\bullet$ & 0 \\
\hline Consistency & 1 & 0.92 & 0.91 & 0.83 & 0.81 & 0.86 & 0.83 \\
\hline Raw coverage & 0.41 & 0.22 & 0.26 & 0.28 & 0.28 & 0.32 & 0.21 \\
\hline Unique coverage $*$ & 0.11 & 0.03 & 0.01 & & & & \\
\hline Overall solution consistency & & 0.94 & & & & & \\
\hline Overall solution coverage & & 0.46 & & & & & \\
\hline
\end{tabular}

= Core condition present, $\otimes=$ Core condition absent, $\bullet=$ Peripheral condition present, $\otimes=$ Peripheral condition absent * Raw coverage, unique coverage and solution coverage are the same when there is only one path for a solution; the same is true for path consistency and solution consistency.

Extensive use of the Internet.

Extensive use of the Internet in business design was associated with multiple intermediate paths. ${ }^{6}$ However, each of these paths is founded on a single parsimonious path, so we have labelled them 1a, 1b, and 1c. A multi-sided market is the core condition present in all three paths. However this condition is not sufficient to explain consistent association with the antecedent, but must be combined with other conditions. Path 1a is the empirically dominant configuration (raw coverage $=.41$, unique coverage $=.11$ ), and combines a multi-sided market with a networked structure. Path $1 \mathrm{~b}$ combines a multi-sided market with the presence of tailored engagement and the absence of repeat payments. Path 1c has the same conditions

\footnotetext{
${ }^{6} \mathrm{We}$ choose not to refer to these as 'equifinal solutions' since causal direction is not established.
} 
as path $1 b$, except that tailored engagement is now absent and repeat payments are present. As is explained in the discussion, the presence of $T$ is often associated with the absence of $R$ and vice versa in our analyses.

Extensive use of quantitative data.

MTR is the only business model configuration that is consistently associated with the extensive use of hard data in business model design (coverage $=.28$ ). Multi-sided markets are a periphery condition, while tailored engagement and repeat payments are core conditions. This was the only configuration in our analyses of the presence of antecedents where $\mathrm{T}$ and $\mathrm{R}$ were present together.

Extensive collaboration of professional external agents.

The extensive inclusion of professional external agents in business creation/reconfiguration process was associated with the $\mathrm{M} \sim \mathrm{RN}$ configuration (coverage $=.28$ ), the absence of repeat payments and presence of a networked structure as core conditions.

Extensive use of business press.

Just under a third of business founders who used texts extensively for business design and validation developed business models with the MTN configuration (coverage $=.32$ ). Tailored engagement and networked structure were core conditions.

Extensive piloting of the new business.

Firms with MT RN business model configurations consistently prototyped their businesses before full commercialization (coverage $=0.21$ )

Table 5: Analysis of antecedents

\begin{tabular}{|c|c|c|c|c|c|c|c|c|c|}
\hline \multirow[b]{2}{*}{ Configuration } & \multicolumn{4}{|c|}{ Feedback } & \multicolumn{4}{|c|}{ Client } & \multirow{2}{*}{$\begin{array}{c}\sim \text { Tools } \\
1\end{array}$} \\
\hline & 1 & 2 & $\mathbf{3 a}$ & $3 \mathbf{b}$ & $1 \mathbf{a}$ & $1 \mathbf{b}$ & 2 & 3 & \\
\hline Multi-sided market (M) & $\otimes$ & 0 & 0 & 0 & $\otimes$ & & 0 & & 0 \\
\hline Tailored engagement $(\mathrm{T})$ & & 0 & & $\otimes$ & & 0 & & $\otimes$ & 0 \\
\hline Repeat payments (R) & & $\otimes$ & 0 & $\bullet$ & $\otimes$ & $\otimes$ & & $\bullet$ & ○ \\
\hline Networked structure (N) & $\otimes$ & & 0 & & $\otimes$ & $\otimes$ & 0 & $\otimes$ & 0 \\
\hline Consistency & 0.80 & 0.90 & 0.93 & 0.91 & 0.87 & 0.92 & 0.89 & 0.92 & 0.82 \\
\hline Raw coverage & 0.51 & 0.20 & 0.22 & 0.24 & 0.36 & 0.30 & 0.32 & 0.25 & 0.19 \\
\hline Unique coverage $*$ & 0.47 & 0.05 & 0.02 & 0.01 & 0.17 & 0.01 & 0.17 & 0.04 & \\
\hline Overall solution consistency & & 0 . & & & & & & & \\
\hline Overall solution coverage & & & & & & & & & \\
\hline
\end{tabular}




\section{Antecedents of Multi-Sided Business Models}

Extensive use of qualitative feedback.

The empirically dominant configuration of this set lacks both multi-sidedness and a networked structure. This configuration accounts for half of all businesses that claimed to have used feedback extensively during their business model implementation (raw coverage $=$ .51 , unique coverage $=.47$ ). Solution 2 combines the presence of multi-sidedness and tailored engagement with the absence of repeat payments (raw coverage $=.20$, unique coverage $=$ 0.05) - however it has a significantly lower coverage than solution 1. Solutions $3 \mathrm{a}$ and $3 \mathrm{~b}$ share the same core condition (repeat payments) and one periphery condition (multisidedness), but differ in that the former also includes a networked structure while the later lacks tailored engagement.

Extensive inclusion of clients.

Solution $1 \mathrm{a}$ and $1 \mathrm{~b}$ share a core condition (non-repeat payments) and a periphery condition (non-networked structure). However 1a combines them with a non-multi-sided market (raw coverage $=.36$, unique coverage $=.17)$, whereas $1 \mathrm{~b}$ combines them instead with tailored engagement (raw coverage $=.30$, unique coverage $=.01$ ). Solution 2 combines the presence of multi-sidedness and networked structure with a similar coverage to solution 1a (raw coverage $=.32$, unique coverage $=.17$ ). Solution 3 lacked tailored engagement and networked structure but had repeat payments, but - like $1 \mathrm{~b}$ - only had limited explanatory power (raw coverage $=.25$, unique coverage $=.04$ ).

The absence of the extensive use of creativity, design or visualization tools.

The absence of the extensive use of design or visualization tools was associated with the MTRN configuration (coverage $=.19$ ), with multi-sided markets, tailored engagement and repeat payments all being present as core conditions. This appears counterintuitive in light of our previous findings; multi-sidedness and networked structures were found either to be present or to be irrelevant in all consistent solution paths for antecedents. In the MTRN configuration, the presence of these two INUS $^{7}$ conditions is associated instead with the absence of an antecedent. We explore this further in the analysis section.

\footnotetext{
${ }^{7}$ Insufficient but Necessary parts of a solution which is itself Unnecessary but Sufficient; cf. Schneider \& Wagemann, (2012)
} 


\section{Antecedents of Multi-Sided Business Models}

\section{Analysis}

This section revisits each question in the light of our results.

\section{Question One: Different Kinds of Involvement}

As expected, we found that the involvement of either current or prospective clients, piloting, and qualitative feedback were each associated with multi-sided, networked models, while quantitative data collection (in combination with other elements) was associated with multisidedness. What is perhaps more interesting is that client involvement and feedback were also consistently associated with the combined absence of both these elements (i.e., single-sided hierarchies). We went back to the cases and discovered that, although these different business models both used the same kinds of antecedents, they did so in different ways.

\section{Client involvement}

For firms that adopted multi-sided, networked models, client involvement was often reciprocal between firms and clients. For example, Case company 6 - an event-based social media platform - reported that prospective clients and early adopters helped establish and scale the venture by promoting it among their peers, so that both users (event seekers) and paying customers (event organizers), benefited from increasing returns of adoption. The CEO of Case company 44 - a brokerage firm that profiles job-seekers - said that client involvement played a "major" role: "[clients] allowed us to adapt our business model according to their expectations".

This firm's clients took an active interest in its development and had expectations about how it should be structured. Interviewees from firms that adopted multi-sided networked models in our study repeatedly reported that clients anticipated benefitting from the new ventures and sought to (a) scale the firm to reap those benefits, or (b) tailor the firm's offerings around their needs.

In contrast, respondents from firms with single-sided, hierarchical models repeatedly stated that, although their clients were involved, that involvement was in response to firm-led initiatives to convince them to take part. The aim of these initiatives seemed to be to benefit the firms, rather than to convince the clients of the mutual benefits to be had: “... [Prospective clients] were not really reactive. It was hard to impose our needs" CEO, case company 51 
Client participation appeared to be far less reciprocal for many such companies than in companies running multi-sided, networked models. Respondents claimed that clients often saw little benefit in involving themselves in the business creation process. The CEO of case company 57 claimed that prospective clients often saw attempts to develop a mutually beneficial model as "insignificant". Interviewees who discussed the role clients played in business creation often described them as gatekeepers who played an all-or-nothing role. For instance, in case company 27 , prospective clients were also prospective investors - according to the CEO, if they had an issue with how the company was developing they would simply not invest.

Despite the fact that both multi-sided, network models and single-sided, hierarchical models in our study consistently involved their clients in business creation/reconfiguration, they did so in different ways. Our interviewees reported that the prospective clients of multisided, networked models were often convinced that they would benefit from the firm's establishment and expansion. They not only assisted in this expansion where they could, but also sought to influence the business model to make it more suited to their needs. In contrast, we found that clients of firms with single-sided hierarchical models were not as convinced that they would benefit from firms' new models. Firms that actively tried to engage prospective clients were often met with indifference, while prospective clients appeared to be more willing to walk away than to try to influence the development of firm models.

\section{Feedback}

As with client involvement, the types of feedback that companies with multi-sided, networked models reported differed from those based on single-sided hierarchies. Our first search found that the only kind of feedback the single-sided hierarchies in our study referred to was product feedback, while firms with multi-sided networks tended to mention services. This result can easily be explained by the fact the multi-sided networks in our study tended to be more service-based, and that both groups were in fact referring to the same thing feedback about their value propositions. But further inspection revealed that firms operating multi-sided, networked models also received feedback about the structures of their businesses. The CEO of company 33 claimed that: "Comments and ratings... [helped] us to improve the system [business] and to evolve with the clients' expectations.", while the company $40 \mathrm{CEO}$ also claimed that the feedback they received formed "... the basis of the business model". 


\section{Antecedents of Multi-Sided Business Models}

\section{Questions Two and Three: Imitation rather than Design}

Curiously, business models that contained the most complex configuration (MTRN) were consistently associated with the absence of the use of design, creativity or visualization tools (henceforth referred to simply as tools). This result runs contrary to our expectations, since we believed greater complexity would require more visualization and problem-solving. To test the robustness of this result we modified the frequency cut-off from two cases to one, but this only confirmed and strengthened our findings - the parsimonious (MTR) solution remained the same and solution consistency rose to .85 . $\mathrm{N}$ disappeared from the intermediate solution: however this implied a superset of the original solution rather than a contradiction since MTR still contains three complex elements the business model overall can still be considered complex.

To understand this result we returned to the cases covered by this solution, and found they were in recruitment, data analytics and short-term leasing. While the business models concerned are complex, they are also well established in these industries, so there would be no need to use tools to reimagine them. The founder of case company 20 dismissed the need for such tools, saying that he was "not a fan" of them. Not only were these models already common in these industries, but the founders also had related experience of working with them: for instance the founder of case company 40 had previously worked with celebrities on a web magazine before developing an online brand management company that used celebrity endorsement. Our data implies that firms with the most complex business models in our dataset were not designed, but were copied from their founders' previous work experience.

Complex business models were also associated with extensive reading about other businesses. Since this solution differed in one condition (repeat payments is a 'don't care'), more business cases were covered by this solution. While it is in line with our expectations about question three - that greater complexity requires new knowledge acquisition and external search - this solution challenges our interpretation of the previous result: that complex business models are replicated from work experience. If that were true, one might expect that their founders would not need to invest time in extensive exploration of texts. To reconcile these two results, we again went back to the cases and found that firms with MT RN models were less well established than their MTRN counterparts: for example, case company 48 won an award for innovation in its field. Closer inspection showed that firms that were novel in their industries or incorporated innovations into their existing models claimed to use text exploration more extensively in their business design than those that used industry-standard business models. The founders we interviewed claimed that they used text 
searches to fill gaps in their own experience, and to validate their business models. While this may sound like a generic claim, only $43 \%$ of all cases reported having used text searches moderately or extensively, and no other business model types were consistently associated with use of texts. It is important to note that the use of texts in business model design is still an exercise in imitation. Rather than reproducing businesses from experience, the founders looked at how other firms had implemented and benefited from their models. The combination of industry experience, learning from others and lack of use of design-thinking tools in implementation of complex business models leads us to propose that business model complexity may be more related to imitation and heuristic reasoning than to creative design.

\section{Question Four: Configurational perspective and overlap}

The results were in line with our expectations; that, a number of radically different business models consistently share similar antecedents, even if similar models do not. This implies that configurational overlap is not an indicator of characteristic overlap. If we were to claim causality, we would say the results demonstrate equifinality. In Feedback, for example, M and $\mathrm{R}$ are both absent in solution 1, but they are also both present in solution 3a. There is no logical contradiction in having opposing models share similar characteristics - just as low and high margin pricing strategies can both be associated with market success - and this phenomenon often indicates complex, synergistic interactions between elements (Fiss, 2011).

As we now discuss - and as Table 6 demonstrates - some of the conditions in these solutions occur together or in opposition repeatedly over a range of solutions.

Table 6: Elemental commonalities between antecedents

\begin{tabular}{|c|c|c|c|c|c|}
\hline & $\mathbf{M}$ & $\mathbf{T}$ & $\mathbf{R}$ & $\mathbf{N}$ & Commonalities \\
\hline Feedback solution 1 & $\otimes$ & & & $\otimes$ & \multirow{2}{*}{$\sim \mathrm{M} ; \sim \mathrm{N}$} \\
\hline Client solution $1 \mathrm{a}$ & $\otimes$ & & $\otimes$ & $\otimes$ & \\
\hline Feedback solution $3 \mathrm{~b}$ & & & & ? & \multirow{2}{*}{$\mathrm{M} ; \mathrm{N}$} \\
\hline Client solution 2 & 8 & & & O & \\
\hline Feedback solution $3 \mathrm{a}$ & & $\otimes$ & 0 & & \multirow{2}{*}{$\sim \mathrm{T} ; \mathrm{S}$} \\
\hline Client solution 3 & & $\otimes$ & 0 & $\otimes$ & \\
\hline Feedback solution 2 & 0 & 0 & $\otimes$ & & \multirow{2}{*}{$\mathrm{T} ; \sim \mathrm{S}$} \\
\hline Client solution $1 \mathrm{~b}$ & & O & $\otimes$ & $\otimes$ & \\
\hline
\end{tabular}


$=$ Core condition present, $\otimes=$ Core condition absent, $\bullet=$ Peripheral condition present,$\otimes=$ Peripheral condition absent

\section{Multi-sidedness and Networked Structure.}

Configurations which include both $\mathrm{M}$ and $\mathrm{N}$ occur as solutions for every antecedent presented in our results. Solution paths without multi-sidedness are always accompanied with a lack of networked structures. There are no solution paths where $\mathrm{M}$ is present and $\mathrm{N}$ is absent, or vice versa. This suggests that the business models in our study that consistently combined these two conditions (in conjunction with others) have similar antecedents.

Business models that contained the conditions of multi-sidedness and networked structure therefore had characteristic overlaps, since they consistently shared the same kinds of antecedents - and the same can be said for models that lacked both these conditions. Our analysis showed that business models that contained one of these conditions but not the other had less characteristic overlaps, since they do not consistently share the same kinds of antecedents. An interesting implication of this is that business models with both $\mathrm{M}$ and $\mathrm{N}$ conditions are more similar to business models that lack both conditions than they are to models which have one of the conditions in common. We can therefore conclude that business models with near identical conditions will not necessarily have overlapping characteristics - and, inversely, that business models which appear to be quite distinct from each other may in fact be similar in certain aspects. In other words, configurational overlap does not necessarily imply characteristic overlap. ${ }^{8}$

Tailored engagement and repeat payments.

With the exception of Data, the presence of tailored engagement is not combined with repeat payments in any of the consistent solution paths revealed by QCA, and the same is true for their absence. Some solution paths combine one of these conditions (or its absence) with the other as a 'don't care'. This implies configurations that combine $\mathrm{T}$ and $\mathrm{R}$ (or $\sim \mathrm{T}$ and $\sim \mathrm{R}$ ) are consistently associated with some antecedents; but where this is true, the opposition of $\mathrm{T}$ and $\mathrm{R}$ is also consistent. Interestingly, there are three antecedents that have two solution paths which are identical except that the presence of $\mathrm{T}$ and absence of $\mathrm{R}$ is reversed (Internet and Feedback both contain MT R and M TR; Client contains $\mathrm{T} \sim \mathrm{R} \sim \mathrm{N}$ and $\sim \mathrm{TR} \sim \mathrm{N})$. This implies consistent associations are only found for these solutions when $\mathrm{T}$ and $\mathrm{R}$ are in opposition.

\footnotetext{
${ }^{8}$ (1) These results do not say anything about the frequency or distribution of business model configurations. Businesses with multi-sided hierarchies and single-sided networks were included in our analyses. (2) The results do not imply that $\sim \mathrm{MN}$ nor $\mathrm{M} \sim \mathrm{N}$ have different antecedents from $\mathrm{MN}$ or $\sim \mathrm{M} \sim \mathrm{N}$. While $\mathrm{MN}$ and $\sim \mathrm{M} \sim \mathrm{N}$ models routinely had the same kinds of antecedents, $\sim \mathrm{MN}$ and $\mathrm{M} \sim \mathrm{N}$ configurations demonstrated less uniformity. (3) Although multi-sidedness and networked structures are often present or absent together, they are not always sufficient in themselves to explain association with antecedents: the inclusion/exclusion of other conditions is often necessary. (4) We should not assume this finding is predictive. Although the consistency scores of solution paths containing $\mathrm{MN}$ or $\sim \mathrm{M} \sim \mathrm{N}$ were above the .8 threshold, none of them had a perfect score of 1.0, so our sample contains a small number of contradictory cases. We see no reason that would prevent an $\mathrm{MN}$ model from being operationalized via venture creation practices that run contrary to these results.
} 


\section{Antecedents of Multi-Sided Business Models}

\section{Discussion}

This study contributes to the business model literature by exploring how different business model types were operationalized at the practical level. We find evidence to suggest that the operationalization of business models is path dependent and related to the experience of venture founders. This paper argues that sixteen potential configurations cover the full variety of empirical business situations; that most businesses can be assigned to one or other business model type; we found that every one of the 77 businesses we sampled could be assigned to one of these configurations. Furthermore, our QCA analyses reveal that consistent patterns do exist between business models and the antecedents of their adoption, and that these relationships imply complex causality. The discussion is organized as follows: first, we discuss the implication of the most surprising result of our analysis, that business model design, creativity or visualization tools were consistently absent in creation/reconfiguration of business with complex business models. Second, we discuss the relationships between antecedents and business models. Third we highlight how a configurational perspective was necessary for us to uncover our findings.

\section{Repositioning Tools}

Surprisingly, the use of tools proposed to help design innovative and complex business models were consistently absent from the implementation of the most complex business models. We interpret this result as a call to be wary about the underlying assumptions of rationality in business design and in the application of design, creativity or visualization tools. According to Osterwalder and Pigneur (2010), such tools are based on rationality: "We design organizations... To do this, we must take into account a complex web of factors... This is precisely what design is about. What businesspeople lack are design tools that complement their business skills.” (p.125)

It is assumed that managers explore a wide range of potential business models to choose the best examples to follow. Usually, as the range of business models is too wide, their searches are limited to existing business models in their industries. Rational business model design is thus constrained by the industry mind-set and limited to existing business models. In response to the notion of rational business design, Loock and Hacklin (2015) argue that the cognitive business modelling process is built on a set of limited number of heuristics resulting from adaptive and individual managerial behaviors. While rational business model design supposes the exploration of all potential possibilities, heuristics are 
idiosyncratic to organizations and usually associated with managerial teams' implicit beliefs. The use of heuristics facilitates adaptive behavior in business model design, enabling flexibility and unity. The cognitive contribution of models needs to be simple enough to be manipulated by managers in a heuristic manner. Models are tools and extensions of heuristic reasoning that differ from rational business design tools which are based on the systematic collection and listing of data. Aversa et al. (2015) propose framing these heuristics with six basic operators (splitting, substituting, augmenting, inverting, excluding and porting) to manipulate them and to process business modelling. Design tools grounded in heuristic reasoning help managers to figure out what could happen if such and such a road were to be followed. Context is introduced during the modelling process, rather than before it.

\section{Business Modelling}

We observed that the types of business models companies adopted were frequently influenced by their histories, the histories of their managers and their firms' relationships with the environment, which emphasizes the path dependent nature of business model adoption. The business modelling process is a result of the articulation of antecedents, founders' experiences, industry influences (Waldner, Poetz, Grimpe, \& Eurich, 2015) and direct environment relationships.

Seeing business models as cognitive tools revisits the traditional debate between emergent and deliberate strategies (Mintzberg \& Waters, 1985). Deliberate strategy is based on rational design and implies the traditional four stage process (scan and search, evaluate, resource, invest) while emergent strategy focuses mostly on strategizing, i.e. the activities involved in designing and implementing strategies. According to Morgan (2012), business modelling represents a new way of reading the environment and its interrelations with the firm, and involves equipping strategy-making with accurate tools to model and prototype business model heuristics. Managers ask different questions, question what is taken for granted and explore potential actions beyond the conventional industry and firm mind sets. Thus business modelling is a way of overcoming managers' cognitive limitations, as well as of coping with the limited rationality that results from their limited cognitive capacities, or from the fuzzy boundaries between firms and their environments. 


\section{Antecedents of Multi-Sided Business Models}

\section{The Configurational Perspective}

We found that multi-sided models were consistently associated with certain antecedents, but only when in combination with other business model elements. We went back to the data to see if those models' antecedents - or combinations thereof - were linked with multi-sidedness as a standalone element, but found no consistent relationships. This emphasizes the need for configuration-based thinking and methods for business model research. Our study demonstrates that certain insights can only be revealed when treating business models as configurations - viewing business model elements in isolation can lead to potential discoveries being overlooked.

\section{Limitations}

Using QCA limited our ability to generalize specific findings beyond our own dataset: however the logic behind our conclusions is not context specific (Fiss, 2011). As is common with most case based research, we cannot make statistical generalizations, although we can make theoretical ones (Yin, 2009). While we should be cautious before claiming what kinds of characteristics are associated with which business models in all incidences, we can claim that business models that appear to be configurationally distant can in fact have more overlapping characteristics than closer ones.

Furthermore, while our analysis highlights patterns of association and emergent themes, our data does not capture the underlying causal mechanisms involved robustly. For instance, we found that multi-sidedness and networked structures were consistently associated with a number of antecedents, but we cannot say we definitively understand why this is the case, nor why this was not true of single-sided networks. Our findings are only implied from patterns of association and reference to our interview data; what we need now is to turn these findings into hypotheses for testing in future research.

\section{Future Research}

Our results point to a number of research opportunities. Our surprising finding about the absence of design, creativity or visualization tools in the design of complex models clearly invites further exploration into the application of such tools and the consequences of using them. More research is also needed to understand how managers who implement multi-sided business models conceptualize, manipulate and communicate about those models without using such tools - what other methods do they use instead? What problems are involved in the manipulation and communication of complex models? In practical terms, we invite the 
development of new heuristic-based tools to support business design and implementation.

Although we have found patterns of association between business model elements, we still need to understand why such patterns occur. Studies that look at the synergies, conflicts, path dependencies, and the like of those business model configurations that repeatedly presented consistent results ( $\mathrm{MN}, \sim \mathrm{M} \sim \mathrm{N}, \mathrm{T} \sim \mathrm{R}$, and $\sim \mathrm{TR}$ ) could help us to understand why they tend to have the same kinds of antecedents.

Methodologically, we invite others to use, adapt or build on our typology to discover other elements that may provide greater explanatory power. Linked to this, we encourage further configurational thinking and methods in business model research to make the complex causal linkages between business model elements, their antecedents and effects, visible for both scholars and practitioners.

\section{Acknowledgements}

We extend our thanks to Charles Baden-Fuller, Tatiana Mikhalkina, and the rest of the Cass team for providing us with an insightful workshop at which to present our preliminary work. Special thanks to Charles-Clemens Rüling and our reviewers, and to participants of the MOTI seminar in Grenoble, and of the ANR project for their meticulous comments. Finally, we would like to thank the ANR (2013 ANR BBM ANR-13-SOIN-0001) and EPSRC for funding this research.

\section{References}

Aversa P., Haefliger S., Rossi A., \& Baden-Fuller C. (2015). Business Model and Modularity. Advances in Strategic Management, Forthcoming.

Baden-Fuller C. \& Haefliger S. (2013). Business Models and Technological Innovation. Long Range Planning, 46: 419-426.

Baden-Fuller C. \& Mangematin V. (2013). Business models: A challenging agenda. Strategic Organization, 11(4): 418-427.

Baden-Fuller C. \& Morgan M. S. (2010). Business models as models. Long Range Planning, 43(2-3): 156-171.

Björkdahl J. (2009). Technology cross fertilization and the business model: The case of integrating ICTs in mechanical engineering products. Research Policy, 38: 1468-1477.

Calia R.C., Guerrini F.M. \& Moura G.L. (2007). Innovation networks: From technological development to business model reconfiguration. Technovation, 27: 426-432

Casey T.R. \& Töyli J. (2012). Dynamics of two-sided platform success and failure: An 
analysis of public wireless local area access. Technovation, 32(12): 703-716.

Chesbrough H.W. \& Rosenbloom R.S. (2002). The role of the business model in capturing value from innovation: Evidence from Xerox Corporation's technology spinoff companies. Industrial and Corporate Change, 11: 533-534.

Chesbrough H.W. (2007a). Business model innovation: it's not just about technology anymore. Strategy \& leadership, 35(6), pp. 12-17.

Chesbrough H.W. (2007b). Why companies should have open business models. MIT Sloan Management Review, 48(2): 22-28

Chesbrough H.W. (2010). Business model innovation: Opportunities and barriers. Long Range Planning, 43(2-3): 354-363.

Day G.S. \& Schoemaker P. (2004). Peripheral Vision: Sensing and Acting on Weak Signals. Long Range Planning, 37(2): 117-123.

Dubosson-Torbay M., Osterwalder A. \& Pigneur Y. (2002). E-business model design, classification, and measurements. Thunderbird International Business Review, 44(1): 5-23

Eisenmann T., Parker G. \& Alstyne M.W.V. (2006). Strategies for Two- Sided Markets. Harvard Business Review, 84: 92-101.

Fiss P. (2007). A Set Theoretic Appraoch to Organizational Configurations. Academy of Management Review, 32(4), pp. 1180-1198.

Fiss P. (2011). Building better casual theories: A fuzzy set approach to typologies in organizational research. Academy of Management Journal, 54: 393-420.

Frankenberger K., Weiblen T. \& Gassman O. (2014). The antecedents of open business models: an exploratory study of incumbent firms. $R \& D$ Management, XLIV(2): 173-188.

Grandori A. \& Furnari S. (2008). A Chemistry of Organization: Combinatory Analysis and Design. Organization Studies, 29(3): 459-485.

Greckhamer T. (2011). Cross-cultural differences in compensation level and inequality across occupations: A set-theoretic analysis. Organization Studies, 32(1): 85-115.

Hacklin F., Marxt C. \& Fahrni F. (2009). Coevolutionary cycles of convergence: An extrapolation from the ICT industry. Technological Forecasting and Social Change, 76(6): 723-736.

Hagiu A. (2009). Multi-sided platforms: From microfoundations to design and expansion strategies. Harvard Business School Strategy Unit Working Paper, (09-115)

Hurley J. (2012). Carlyle Group eyes £50m deal for 'snacks by post' company Graze. [Online] Available at:

http://www.telegraph.co.uk/finance/newsbysector/retailandconsumer/9484420/CarlyleGroup-eyes-50m-deal-for-snacks-by-post-company-Graze.html [Accessed 28 Nov 2014].

Larsen M.M., Manning S. \& Pedersen T. (2013). Uncovering the hidden costs of offshoring: The interplay of complexity, organizational design, and experience. Strategic Management Journal, 34(5): 533-552.

Loock M. \& Hacklin F. (2015). Business Models as confuguring Heuristics. Advances in Strategic Management, forthcoming.

Markides C. (2006). Disruptive innovation: In need of a better theory. Product Innovation Management, 23: 19-25.

McGrath R. (2010). Business models: a discovery driven approach. Long Range Planning, 43(2-3): 247-261. 
McPhillips S. \& Merlo O. (2008). Media convergence and the evolving media business model: an overview and strategic opportunities. The Marketing Review, 8(3): 237-253.

Miller D. (1990). Organizational configurations: Cohesion, change, and prediction. Human Relations, 43: 771-789.

Mintzberg H. \& Waters P. (1985). Of strategies deliberate and emergent. Strategic Management Journal, 6: 257-272.

Montgomerie J. \& Roscoe S. (2013). Owning the consumer-Getting to the core of the Apple business model. Accounting Forum, 37(4): 290-299.

Morgan M. (2012). The World in the Model: How Economists Work and Think. Cambridge: Cambridge University Press.

Mullins J. \& Komisar R. (2009). Getting to Plan B: Breaking Through to a Better Business Model. Boston: Harvard Business Press

Øiestad S. \& Bugge M.M. (2014). Digitisation of publishing: Exploration based on existing business models. Technological Forecasting and Social Change, 83: 54-65.

Osterwalder A. \& Pigneur Y. (2010). Business Model Generation. Hoboken, New Jersey: John Wiley and Sons, Inc..

Parmentier G. \& Mangematin V. (2014). Orchestrating innovation with user communities in the creative industries. Technological Forecasting and Social Change, 83(1): 40-53.

Ragin C.C. (1987). The Comparative Method. Berkeley: California University Press.

Ragin C.C. (2000). Fuzzy Set Social Science. Chicago: Chicago University Press.

Ragin C.C. (2006). Set relations in social research: Evaluating their consistency and courage. Political Analysis, (14): 291-310.

Ragin C.C. (2008). Redesigning social inquiry: Fuzzy sets and beyond. Chicago: University of Chicago Press.

Ragin C.C. \& Fiss P. (2008). Net effects analysis versus configurational analysis: An empirical demonstration. In: Ragin \& C. C, eds. Redesigning social inquiry: Fuzzy sets and beyond. Chicago: University of Chicago Press: 190-212.

Ragin C. \& Davey S. (2014). fs/QCA [Computer Programme], Version 2.5. Irvine, CA: University of California..

Rayna T., Darlington J. \& Striukova L. (2014). Pricing music using personal data: mutually advantageous first-degree price discrimination. Electronic Markets: 1-16.

Rayna T. \& Striukova L. (2010). Large-scale open innovation: open source vs. patent pools. International Journal of Technology Management, 52(3): 477-496.

Reis E. (2011). The Lean Startup: How Today's Entrepreneurs Use Continuous Innovation to Create Radically Successful Businesses. New York: Crown Publishing Group

Reynolds N. \& Ruiz de Maya S. (2013). The impact of complexity and perceived difficulty on consumer revist intentions. Journal of Marketing Management, 29(5-6): 625-645.

Rihoux B. \& Ragin C.C. (2009). Configurational Comparative Methods: Qualitative Comparative Analysis (QCA) and Related Techniques. London: Sage.

Rochet J.C. \& Tirole J. (2008). Tying in two-sided markets and the honor all cards rule. International Journal of Industrial Organization, 26(6): 1333-1347.

Rochet J.-C. \& Tirole J. (2003). Platform Competition in Two-Sided Markets. Journal of the European Economic Association, 1(4): 990-1029.

Sabatier V. Mangematin V. \& Rousselle T. (2010). From Recipe to Dinner: Business Model 
Portfolios in the European Biopharmaceutical Industry. Long Range Planning, 43(2-3): 431-447.

Schneider C.Q. \& Wagemann C. (2012). Set-Theoretic Methods for the Social Sciences: A Guide to Qualitative Comparative Analysis (Strategies for Social Inquiry). Cambridge: Cambridge University Press.

Shafer S.M., Smith H.J. \& Linder J. (2005). The power of business models. Business Horizons, 48: 199-207

Smith W.K., Binns A. \& Tushman M.L. (2010). Complex business models: Managing strategic paradoxes simultaneously. Long Range Planning, 43(2): 448-461.

Teece D.J. (1986). Profiting from technological innovation: Implications for integration, collaboration, licensing and public policy. Research policy, 15(6): 285-305.

Teece, D.J. (2010). Business Models, Business Strategy and Innovation. Long Range Planning, 43(2-3): 172-194.

Timmers P. (1998). Business models for electronic markets. Electronic Markets, 8(2): 3-8

Waldner F., Poetz M.K., Grimpe C. \& Eurich M. (2015). Antecedents and consequences of business model innovation: The role of industry structure. Advances in Strategic Management, forthcoming.

Wood R.E. (1986). Task complexity: Definition of the construct. Organizational behavior and human decision processes, 37: 60-82.

Yin R. (2009). Case Study Research: Design and Methods, 4th ed.. London: Sage publications.

\section{Biographies}

Ryan Rumble is a PhD student at Grenoble Ecole de Management. He researches when and how business models are used in strategic imitation processes and is particularly interested in innovation and mimicry in retail. Grenoble Ecole de Management 12, rue Pierre Sémard, 38000, Grenoble, France.e-mail: ryan.rumble@grenoble-em.com

Vincent Mangematin is a professor and scientific director at Grenoble Ecole de Management. He researches the transformative influence of digital technologies, focusing on business models as an approach to renew strategy. He is associate editor of Technovation and M@n@gement and serves on the editorial boards of Organization Studies, Research Policy and Long Range Planning. Grenoble Ecole de Management 12, rue Pierre Sémard, 38000, Grenoble, France.e-mail: vincent.mangematin@grenoble-em.com works: http://scholar.google.fr/citations? user $=s M 8-l o E A A A A J \& h l=f r$. 


\section{Appendix A: List of Antecedents}

Interviewees were asked to assess to what extent the following practices were performed specifically for the design or implementation of the business in question. They were also asked to elaborate on how they performed the activity.

\section{Antecedents related to question one}

- Include current or prospective clients

- Pilot test the business

- Gather and analyze qualitative feedback

- Gather and analyze quantitative data

\section{Antecedents related to question two}

- Use business design, creativity or visualization tools (e.g. the Business Model Canvas, the Board of Innovation)

\section{Antecedents related to question three}

- Read business press (e.g. popular press, scientific papers, reports commissioned by others)

- Perform internet searches and browsing ${ }^{9}$

- Include professional agents (e.g. consultants, incubators)

\footnotetext{
${ }^{9}$ This antecedent could be considered redundant if the internet was used to access texts or business model design tools. However preliminary interviews suggested that the internet was also used less formally (e.g. for browsing)
} 